\title{
Mídia e educação: em cena, modos de existência jovem *
}

\section{Media and education: on the scene, ways of young existences}

\author{
Rosa Maria Bueno Fischer**
}

\begin{abstract}
RESUMO
Neste artigo, o propósito é articular o depoimento de jovens de 15 a 25 anos com o que deles falam os diferentes produtos da mídia, especialmente a televisão. A partir da escuta de estudantes de escolas públicas e privadas, selecionou-se um tema principal para a análise dos modos de existência jovem: a construção do "outro" nos meios de comunicação e a relação desses grupos com as diferenças sociais, econômicas, geracionais, raciais e étnicas, de gênero e de aparência física. Com apoio em Michel Foucault, particularmente nos conceitos de normalidade, anormalidade e modos de subjetivação, discutimos as formas pelas quais a sociedade do espetáculo e da imagem opera na nomeação e na construção dos "outros jovens", e como esse processo circula entre estudantes de nível médio e universitário no meio urbano de Porto Alegre, RS. Para tanto, recorremos também a autores como Jorge Larrosa e Maria Rita Kehl, com o objetivo de pensar de que forma se configura na mídia uma espécie de "normalidade jovem". Sugerimos, nas conclusões, que, a partir dos debates e da análise das produções midiáticas, haveria a possibilidade de pensar outros modos de existência para grupos juvenis em nossa cultura.

Palavras-chave: mídia, juventude, televisão, diferença, normalidade, cultura.
\end{abstract}

* Pesquisa apoiada pelo CNPq (auxílio individual e bolsa de produtividade)

** Doutora em educação. Professora da Faculdade de Educação e do Programa de PósGraduação em Educação da Universidade Federal do Rio Grande do Sul (UFRGS). Pesquisadora do CNPq na área temática de mídia, cultura e educação. E.mail: rosabfischer@terra.com.br 


\begin{abstract}
The aim of this paper is to articulate young voices and media products addressed to the public from 15 to 25 years old. Starting from debates with students from private and public schools, I analyzed how media is constructing "the other", in terms of economical, racial and ethnic differences; also in terms of differences of gender, age and physical appearance. The theoretical references are Foucault's concepts of normality, abnormality and ways of subjectivation, in order to discuss how our society of image and spectacle nominates the "young others", and how students from Porto Alegre (Brazil), realize this process. I also used the contribution of Maria Rita Kehl and Jorge Larrosa, to think about a "young normality" in Brazilian media. At the conclusion, I suggest that debates and analysis about media, in student's company, represent a strong possibility of imagining new forms of young existences in our culture.
\end{abstract}

Key-words: media, youth, television, difference, normality, culture.

Neste texto, o objetivo é estabelecer um diálogo entre a análise de produtos midiáticos e o depoimento de jovens estudantes a respeito de sua relação com os meios de comunicação. Trato de produtos destinados ao público juvenil, especialmente pelos canais de TV aberta e a cabo, no Brasil, problematizando o discurso da mídia e os modos de existência jovem nele propostos, em contraponto com a experiência de grupos de estudantes, diante dos materiais culturais que lhes são oferecidos, e de modo particular no que se refere às afirmações que fazem de si mesmos, sobre as temáticas aí transformadas em imagens, textos, seqüências, cores e sons.

No centro das atenções está um grupo que, no Brasil, chega a aproximadamente 35 milhões de pessoas (jovens de 15 a 25 anos), e sobre o qual disseminam-se inúmeros "ditos" já cristalizados como senso comum, associando juventude a violência, a consumismo, apatia, gravidez precoce, sexo irresponsável, e assim por diante. ${ }^{1} \mathrm{~A}$ idéia é, conforme a pesquisa que realizamos

1 Observações semelhantes encontram-se em vários estudos recentes sobre juventude. Ver, a propósito, ABRAMO; FREITAS; SPOSITO (Orgs.), 2000. Ver também Abramo (2005). 
de 2002 a 2005,,$^{2}$ expor e discutir, a partir das falas dos próprios jovens, sua condição de alvo desses ditos do senso comum, que circulam em vários lugares sociais, mas sobretudo nos meios de comunicação - esse lugar de construção e veiculação de "verdades". Em suma, o propósito é colocar em debate o depoimento vivo dos jovens, mostrando a articulação de seus temores, insatisfações, perplexidades, críticas, amores, com o que deles falam os diferentes produtos da mídia, especialmente a televisão. Em virtude do grande volume de dados, selecionamos um tema principal relativo aos modos de existência jovem em circulação na cultura: a relação com as diferenças - sociais, econômicas, geracionais, de aparência física, raciais e étnicas, de gênero, entre outras.

Assim, tenho como objetivo pensar os modos como se constroem na cultura alguns processos de produção dos sujeitos jovens, entendendo aqui, com Michel Foucault (1986; 1990; 1995; 2004), que somos permanentemente constituídos por diferentes discursos, ou seja, nos tornamos sujeitos de certas verdades, no interior de determinados regimes de poder. Na concepção foucaultiana, porém, o fato de nos tornarmos sujeitos de verdades não impede - pelo contrário, supõe - que os sujeitos também se constituem a si mesmos, para além daquilo que lhes é oferecido como norma ou regra de vida. Neste texto, levo em conta essa idéia complexa da produção de modos de existência na cultura (especialmente pela ação dos meios de comunicação), articulando-a a outros conceitos relativos à construção dos "outros" e das diferenças em nossa sociedade (LARRosA, 2004; COSTA, 2004; KEHL, 2004; FOUCAULT, 2001). Importa pensar de que forma algo se configura como "normalidade jovem" e, ao mesmo tempo, de que forma algumas proposições irrompem como acontecimento, como possibilidade de "pensar de outro modo" a vida de homens e mulheres de 15, 20 ou 25 anos neste país. Passo a discutir de que modo alguns grupos jovens se relacionam com a mídia, especialmente com a TV, para depois mapear modos de existência debatidos pelos estudantes, convidados a analisar as imagens televisivas e a pensar sobre suas próprias experiências cotidianas.

2 Refiro-me à pesquisa "Mídia, juventude e reinvenção do espaço público", realizada de 2002 a 2005. Basicamente, os dados foram levantados a partir da transcrição de aproximadamente 50 horas de gravações de programas de TV destinados ao público de 15 a 25 anos ou que fazem referência explícita a esse grupo (por exemplo, a novela teen Malhação, da Rede Globo); e dados referentes a 23 encontros com seis grupos de recepção (estudantes de Ensino Médio de duas escolas públicas e uma particular e de uma escola pública de educação de jovens e adultos, além de jovens de dois cursos - Comunicação e Pedagogia - de uma Universidade Federal). (FISCHER, 2005). 


\section{A TV como agenda e como exercício da crítica}

De modo geral, pode-se dizer que para os seis grupos com os quais a equipe de pesquisa entrou em contato, a televisão é parte indiscutível do cotidiano: é necessidade, é presença, é lazer e companhia. É também fonte de crítica mas é, sobretudo, lugar a partir do qual se fala em acolhida, como se de fato a TV operasse como uma grande "mãe cultural", que nos diz: "Vem, me veja, olhe e se olhe, porque você está aqui". Não só a TV, mas as revistas, como Capricho, ${ }^{3}$ são lembradas como lugar que os acolhe, especialmente no que se refere às inúmeras indagações que têm sobre corpo e sexualidade. Os inúmeros relatos foram dando conta de que a TV funciona como modo de pertencimento, de participação em relação a algo que é público. Há, em programas como Big Brother Brasil, ${ }^{4}$ por exemplo, a oferta de múltiplas identificações. Cada um encontra nos diferentes produtos televisivos alguma possibilidade de afirmar: "Eu estou ali", "isso me toca", "eu sou bem parecido com essa pessoa".

Num tempo em que nos voltamos tão avidamente para a vida privada, imersos numa cultura profundamente narcísica, falar sobre a TV em nosso cotidiano conduz os jovens a pensarem sobre a solidão, associada à prática diária e simplória de comer diante da TV. Da mesma forma - e isso apareceu mais fortemente nos depoimentos em escolas públicas -, os alunos associam a problemas cruciais da juventude de camadas populares o hábito de assistir muitas horas diárias (até seis) à TV. Numa frase, a síntese de uma das alunas: "Não tem nada pra fazer". No comentário a seguir, o drama vivido por muitos deles: "Melhor ficar em casa vendo novela do que na rua, não tem o que fazer. [Em vez de] fazer na rua o que não deve": "cheirar, fumar, se prostituir". Outro aluno completa: "Na rua é perdição". Essa oposição entre mundo da rua e mundo da televisão parece indicar uma precariedade da nossa vida pública, fato que nos conduziria "naturalmente" à televisão - um lugar que, além de tudo, nos é mostrado como democrático, igualitarista, nivelador, como escreve a crítica argentina Beatriz Sarlo (1997).

Cinema, teatro, filmes em vídeo, essas são opções que existem apenas para os que "têm dinheiro", e este não é o caso de grande parte dos alunos de

3 Revista quinzenal editada pela Abril, e destinada ao público adolescente feminino.

4 Reality show conhecido por $B B B$, veiculado pela Rede Globo e que já teve sua quinta edição em 2005. 
escolas públicas. Nesse sentido, aliás, nossa pesquisa corrobora os dados de outras investigações, como a do Instituto de Cidadania, "Perfil da juventude brasileira", de 2003, que aponta entre outros dados os desejos não realizados de jovens brasileiros de 15 a 24 anos, quanto a lazer e entretenimento (ABRAMO, 2005 , p. 54). No caso dos grupos de escolas públicas que entrevistamos, o que os tira da TV é a própria escola e também algumas "comunidades", de pagode, de dança, do CTG (Centro de Tradições Gaúchas), assim como atividades esportivas, especialmente jogo de futebol. Mesmo considerando estudantes de nível universitário e alunos de escolas particulares, pode-se dizer que para a maioria deles existe, concretamente, a dificuldade financeira de freqüentar cinema e teatro, o que acaba por conferir à TV um papel maior ainda no que se refere às opções de lazer ${ }^{5}$ e de contato com narrativas de ficção: assistir a filmes na televisão parece ser uma prática das mais efetivas entre os estudantes de todos os grupos de recepção, confirmando dados de pesquisas de mais de 20 anos, que mostram o quanto os públicos infantil, adolescente, juvenil (e adulto também) buscam na TV principalmente um modo de interagir com a ficção, a narrativa, o drama. ${ }^{6}$ Esse tema, aliás, é alvo de uma das críticas mais ácidas à TV, do estudioso Teixeira Coelho (1991), que analisa o imaginário construído pela televisão brasileira, segundo ele, ainda calcado num ideário maniqueísta, em que o Bem se vincularia primordialmente à competitividade, à violência e à própria morte da imaginação. Teixeira está de acordo com o que escreve a psicanalista Maria Rita Kehl, para quem as narrativas televisivas, especialmente aquelas mostradas pelos "dramas" dos reality shows, apelariam para a brutalidade, o sentimentalismo e a "burrice exibicionista", justamente num tempo em que estamos vivendo uma espécie de "estreitamento de nossa imaginação" (KEHL, 2004, p. 165-173).

Ora, podemos identificar nos depoimentos muitos aspectos dessa argumentação, tanto de Maria Rita Kehl como de Teixeira Coelho. Porém, é preciso reconhecer: se a TV é presença constante na vida de todos os grupos estudados, parece ser, simultaneamente, objeto permanente de críticas. Ou seja, o debate permitiu abrir espaços para algo mais, além da adesão pura e

5 Na análise que Helena Wendel Abramo faz da pesquisa citada, do Instituto Cidadania, a socióloga ressalta que as questões de cultura e lazer, tão importantes nessa faixa etária, não aparecem nas entrevistas como um tema de direito para eles - talvez, por uma "desvalorização social geral [da cultura e do lazer] como assunto de resolução pública” (ABRAMO, 2005, p. 66).

6 Esses dados repetem conclusões de outras investigações, como a que realizei nos anos 80, com crianças e adolescentes de camadas populares do município do Rio de Janeiro (ver FISCHER, 1993). 
simples dos jovens à mídia televisiva e a seus imaginários. De uma maneira geral, pode-se dizer que o próprio tema dos meios de comunicação seria mobilizador da crítica aos processos nomeados pelos jovens como "manipulação", e registrados em todos os grupos de recepção. A prática cotidiana de assistir à TV e de comentar o que se vê acaba por "ensinar" a esses jovens algo das estratégias da mídia e do mercado, neste tempo de publicidade e de valorização extremada da imagem.

Debater os modos pelos quais a TV faz parte da vida dos jovens, em outras palavras, leva a olhar criticamente, com os estudantes entrevistados, não só para outras formas e meios de comunicação (cinema, Internet), como para a própria televisão: os jovens oscilam entre o reconhecimento de que programas como Malhação, ${ }^{7}$ por exemplo, atraem porque "mostram a sociedade", e ao mesmo tempo o fato de que tais produtos provocam alguma rejeição, à medida que ali se configuraria o reino da artificialidade e da mesmice. "A história é sempre a mesma" - como diz um dos alunos. E se os temas se repetem, as próprias polêmicas seriam sempre as mesmas: amores proibidos, conflitos entre ricos e pobres, medo dos diferentes (homossexuais, por exemplo). É como se a ameaça do outro rondasse muitos desses produtos e fosse necessário sistemática e quase compulsivamente exorcizar, sobretudo, as diferenças de sempre (como as de classe, de etnia, de escolha sexual).

\section{A mídia, o jovem e a classificação do "outro"}

Dentre as críticas mais fortes manifestadas pelos grupos de recepção está a de que a TV não se cansa do recurso à “classificação do outro". Haveria uma constante exposição não só dos tipos de pessoas ou de modos de ser que seriam desejáveis na sociedade, mas também daqueles que "deveriam" de alguma forma ser excluídos. Com o avanço das novas tecnologias e do acesso a tantas imagens e a tanta informação, talvez tenhamos chegado a um momento extremo no processo de individuação e classificação dos sujeitos, para a intensificação do controle sobre a sociedade - processo do qual nos fala Foucault em suas obras, sobretudo em Vigiar e punir (1991), e no curso Os

7 Novela teen veiculada no final da tarde pela Rede Globo, no ar há dez anos. 
anormais (2001). Todas as diferenças podem ser mostradas, mas há que reuni-las em blocos, há que nomeá-las e dizer o que há nelas de conveniente, correto, certo; também o que há nelas de problemático, a rejeitar, a afastar para bem longe.

Entre as estudantes de Pedagogia, examinar programas como o $B B B$ permitiu que elas expressassem detalhes de como percebem as estratégias de captura dos diferentes públicos: as alunas entendem que os telespectadores, especialmente os jovens, tornam-se alvo de uma curiosidade criada, uma "curiosidade de saber" - ou uma "vontade de saber", como diria Foucault (1990); há também o apelo ao envolvimento com figuras-tipo (a professora nordestina pobre, o rapaz "malhado", a "miss", a babá, o homem gay, e assim por diante), que de alguma forma tocam as pessoas, pelo que representam como figuras masculinas ou femininas, como homens e mulheres de uma determinada classe social, profissão, idade, com um certo tipo de padrão corporal, um certo "jeito de ser da pessoa". Cada um delineia-se como um show à parte, alguém a ser desejado, em virtude, principalmente, de sua performance midiática.

Estamos efetivamente no centro do que Guy Debord (2002) chamou de "a sociedade do espetáculo". É disso que falam essas alunas, quando lembram o fato de o apresentador do $B B B$, Pedro Bial, tratar os participantes do programa como "heróis". Essa observação levou-as a pensar sobre a TV como um espaço que se oferece como lugar da perfeição, em que desfilam pessoas e objetos inalcançáveis, em comparação com as vidas simples dos "pobres mortais". Uma das alunas expressou isso muito bem:

... parece que a nossa vida nunca tá perfeita, porque eles são os perfeitos (...). Isso gera uma insatisfação, porque daí não se fica satisfeito com o próprio corpo, porque o corpo que se vê na TV é o corpo sarado, malhado. [Também] não se fica satisfeito com o próprio trabalho, porque o trabalho dos caras na TV é um trabalho que permite a eles terem tempo de ir pra academia, de cuidarem dos filhos, e eu não tenho nada, e aí tu não tem nenhum pouco daquilo que colocam ali como correto e aí tu quer mais é sair um pouco da tua realidade e entrar naquilo ali.

Poderíamos dizer aqui que haveria uma grande cisão entre "nós" e "os outros", considerando as pessoas e grupos mostrados na TV e as pessoas e grupos que ficam do lado de cá, os espectadores. Essa seria a primeira divi- 
são, a primeira classificação, no sentido foucaultiano: haveria um mundo desejado, um mundo da perfeição, ao qual somos convidados insistentemente, mas que permanece inalcançável, embora, de modo contraditório, se ofereça como possível - à medida que quase todos os programas de TV cada vez mais se caracterizem por reproduzir o cotidiano, a "realidade", a vida comum das pessoas.

No texto "Três observações sobre os reality shows", a psicanalista Maria Rita Kehl (2004) nos ajuda a pensar sobre a mídia como instância que, cada vez mais, estaria ocupando os espaços públicos. Giramos em torno da televisão, mesmo que ali estejamos sendo colocados diante da nossa própria miséria de "vida pública", a qual se retrai progressivamente, junto com os espaços de criatividade e de invenção de novos modos de existência. Giramos em torno da telinha, mesmo nos dando conta de que a dimensão pública de nossa vida está sendo sacrificada. Grudamos os olhos na TV, mesmo que percebamos, como as estudantes de nossa pesquisa, o quanto há de exibicionismo na tela e o quanto somos por vezes humilhados.

O sentimento manifestado pelas alunas de Pedagogia, de diminuição de si mesmo (o sentimento de que "eu não tenho nada", "eu não sou nada" diante daquilo que está na TV) e de entrega ao que lhes é oferecido como belo e desejável, remete-nos a um problema mais amplo, da produção e da afirmação permanente da desigualdade, e que não é privilégio dos meios de comunicação. $\mathrm{Na}$ análise das diversas formas de relação com o "outro", propostas pela mídia, e comentadas pelos seis grupos de estudantes, começamos a perceber que nossa sociedade, como já nos tinha alertado Foucault (1991), cada vez mais se sofistica em aperfeiçoar mecanismos de divisão entre os sujeitos, de tal forma que, hoje, embora com todas as conquistas de lutas e movimentos sociais, num país como o Brasil, ainda assistimos a práticas e discursos que não se cansam de diminuir o outro, de rebaixá-lo, de arrogantemente menosprezá-lo e humilhá-lo, sempre sob novas e sutis formas.

Jorge Larrosa (2004), no texto "Educação e diminuição", sublinha o papel da educação formal nessa prática cotidiana de espezinhamento do outro, de elevação de si pelo rebaixamento do outro - e que percebemos estar mais do que nunca presente nos materiais televisivos, que analisamos e discutimos com os jovens de nossa pesquisa. Interessante a destacar é o casamento entre as práticas de pedagogia escolar e as práticas da pedagogia midiática: ambas se irmanam na produção diária da desigualdade, a partir especialmente de um olhar que identifica, classifica e ordena, produz e reproduz corpos, objetiva sujeitos, esforça-se em reduzir diferenças e em aplainar possibilidades de surpresa ou experiências não pensadas. 


\section{Eu sou normal? ou: os diferentes na vida e na mídia}

Talvez uma das temáticas mais presentes em todos os 23 debates realizados com os seis grupos tenha sido aquela que se refere à pergunta que atormenta grande parte dos jovens: eu sou normal? Nos encontros, a discussão partia ora do exame de um filme como Matrix, ${ }^{8}$ ora dos comentários sobre Big Brother Brasil ou sobre uma reportagem do Jornal Nacional a respeito de tribos adolescentes no Brasil. Eles manifestaram perceber a força do social, da família, da escola e de outras instituições, na constituição dos modos de ser desejados e desejáveis, considerados normais. Como diz uma das alunas da escola particular, "o problema é que se tu não é determinado tipo de pessoa que querem que tu seja, sabe, tu é considerada maluca, louca, sabe?! Tu não é considerada a normalzinha da sociedade. Então tu tem um padrão desde pequena”. Eles percebem que não vem somente do mundo adulto a cobrança de uma normalidade: os colegas também excluem aquele que não se enquadra nos padrões do pequeno grupo. E as exclusões passam por particularidades como a roupa que alguém veste, uma "calça inútil", que "não é de marca".

A apresentação do vídeo com uma reportagem sobre jovens no Brasil" foi motivo para os alunos da escola particular exporem uma quantidade interminável de classificações e subclassificações que ocorrem no cotidiano dos jovens: um "nerd", por exemplo, é o "idiota" (como exemplo, citam Bill Gates e todos os hackers, os estudiosos, entre outros "retardados"). Uma "paty" poderá ser "paty de roupa" e "paty de cabeça"; existem mulheres "galinhas" e homens "boyzinhos", homens pegadores, mulheres putas, vagabundas. O debate chega a detalhes inimagináveis: uma roupa da moda só será realmente bem avaliada se o modelo e o tamanho forem exatamente aqueles considerados desejáveis: como admitir alguém que compra uma camisa "três números menor que o [tamanho] dele?". Nesse momento do debate, cresce no grupo a exposição inflamada de um sem-número de regras de consumo, de apresentação pública, de como se vestir para ser aceito num certo grupo, num certo

8 Filme realizado por Andy Wachowski e Larry Wachowski (EUA), em 1999. Seguiram-se Matrix Reloaded e Matrix Revolutions (ambos de 2003). A trilogia de filmes de ficção científica parece fascinar os adolescentes, talvez por tratar da possibilidade de existência de um sistema artificial a manipular a mente das pessoas, e por confundir realidade e ficção, bem como por tocar no grande tema da liberdade.

${ }^{9}$ Matéria veiculada no Jornal Nacional - Especial Juventude Urbana, de 19/06/2003, da Rede Globo. 
tempo específico - regras "naturalmente" aceitas e em nada parecendo compatíveis com toda a crítica feita à mídia, às instituições, a tudo e a todos que constrangem os mais novos a serem deste e não daquele modo. As regras parecem ser propriamente deles, incorporadas como indiscutíveis.

O tema da classificação do outro (e de sua conseqüente exclusão) mobilizou todos os grupos participantes da pesquisa; num dos casos (na escola particular), meninos e meninas demonstraram uma espécie de prazer sádico nessa experiência de negar o diferente - prática possivelmente relacionada com a própria não-aceitação do que cada um rejeita em si mesmo; mas uma prática seguramente violenta e muito de perto relacionada às divisões sociais mais amplas, pelas quais nossa sociedade considera alguns como cidadãos, outros como subcidadãos, como refere o sociólogo Jessé de Souza em seu livro A construção social da subcidadania (2003). Assim, nessa escola, eles contam como foram sucessivamente classificando uma menina que tinha cabelo crespo: primeiro, era alcunhada de "repolhuda"; quando cortou bem curto o cabelo, seu nome passou a ser "piolhuda". A menina que narra a história conclui: "Pra dar a volta, tu te adapta ao que as pessoas querem. Tipo, agora, ela é uma baita duma "paty". O grupo continua criticando a menina, que mudou para se adaptar e se tornar "normal": "Ela só se preocupa com coisas fúteis", diz a colega, referindo-se às contínuas mudanças do cabelo, e à suposição de que a menina super-classificada agia assim para "virar uma pessoa melhor".

Torna-se difícil para os jovens perceberem o quanto eles mesmos estão submetidos às próprias classificações que praticam no cotidiano. Perguntados sobre isso, respondem que julgam o outro porque ele foge ao padrão, à normalidade. Muitas vezes, buscam justificativas para esse gesto: "Eu acho que não tem uma explicação por que o ser humano tem necessidade de classificar os outros, [talvez seja para] organizar melhor o mundo que está em volta dele". Uma menina complementa o colega: "Eu acho que de repente (...) tu te sente frágil em algum ponto e tu vai falar do outro, te defende..." . Uma das alunas do primeiro semestre de Comunicação é enfática e vai direto ao ponto: para ela, os modos como aprendemos a construir nossa identidade passam necessariamente pelo julgamento e pela classificação e diminuição do outro: [Aprendo que] "pra eu me sentir bem, eu tenho que saber que as pessoas que estão à minha volta têm defeitos também”. Ora, é justamente essa a discussão que faz o professor espanhol Jorge Larrosa, quando escreve que a codificação do outro está relacionada à busca de tornar compreensível algo que, talvez, seja da ordem do inapreensível, do imprevisível, do provisório; mas se trata de uma busca em que as pessoas acabam por comprazer-se no exercício da codificação, a partir da nomeação de si mesmo como normalidade, como su- 
jeito-bem-situado, no interior de um processo de construção vertical do outro, como alguém deslocado, insubmisso, alguém que deveria ser outra coisa, não o que é.

Olhar "de cima", como escreve Larrosa (2004, p. 277), é olhar com distância; é olhar a partir do que falta no outro. Essa seria uma das características básicas do discurso pedagógico. Aliás, a competência a ser adquirida para fazer parte desse lugar institucional e de saber - a escola e o pensamento pedagógico - seria justamente aprender a perceber e a identificar a falha, o buraco, o que está incompleto, e então, a partir daí, empreender projetos de completude, de reforma e melhorias. A meu ver, os produtos midiáticos, em especial aqueles destinados aos públicos infantil e juvenil, parecem não fugir a essa mesma proposta; parece que não vivem sem, obstinadamente, apontar as insuportáveis falhas das meninas que estão gordas demais, dos meninos que se drogam demais, das jovens que engravidaram cedo demais. Tudo é "demais", tudo seria demasiado diferente, e é preciso corrigir tanta falha, tanta falta de normalidade.

Penso que um dos paradoxos, no caso da mídia - nesse afã de classificar, julgar, separar e chamar à normalidade -, seria o de que justamente nesse lugar se faz uma interpelação a partir de indivíduos que se destacam, de alguém que se faz herói, fenômeno ou celebridade, de alguém que consegue distanciar-se das pessoas comuns. Portanto, parte-se de alguém quase fora do "normal", justamente para chamar à normalidade, para criticar o desvio da norma. Num dos encontros com calouros do Curso de Comunicação, o debate sobre os "outros" levou o grupo a discutir diretamente o tema da diminuição do outro: o gordo, o que tem espinha no rosto, o que foi ou é repetente, os chamados "burros" e fracassados, os magrelas, etc. Conforme eles disseram, qualquer fato, qualquer dado, qualquer marca do corpo poderá ser motivo para "pisarem no teu pé", para carimbarem o sujeito.

Ao mesmo tempo em que tais classificações parecem ser tão divertidas para quem cria o nome ou o carimbo, também parece evidenciar-se e exercerse, segundo os depoimentos, uma extrema violência sobre o sujeito classificado. Uma menina poderá ser chamada de "ovo frito", porque tem pouco volume de seios; poderá ser julgada "burra" porque tem muito pêlo no corpo - e essas histórias são narradas com muito humor, carregando também a marca não só do sofrimento individual, psíquico, como a marca de uma época que se caracteriza pelas mais sofisticadas operações sobre o próprio corpo, para fazê-lo "normal", desejável para este tempo. A menina "ovo frito", segundo narram, está fazendo poupança para colocar silicone nos seios, no rastro do exemplo de atrizes e apresentadoras de TV, que se tornam modelos de corpos inatingíveis, inclusive para elas mesmas (as atrizes), já que sempre 
haverá algo a corrigir, a aperfeiçoar, a melhorar. Como bem lembra o psicanalista Jurandir Freire Costa (2004), hoje, como nunca, estamos acuados pela dor e pelo medo de nosso corpo não ser causa do interesse do outro. Haveria, segundo o autor, uma espécie de ideologia somática, hegemônica em nossos tempos, de acordo com a qual só seremos felizes se aceitarmos que a felicidade é sinônimo de satisfação sensorial (COSTA, 2004, p. 186), portanto, de hipercuidado com a aparência, a juventude, a longevidade, as formas do corpo.

A mídia teria, segundo uma estudante do Curso de Comunicação, papel fundamental em tudo isso, "porque ela diz que o padrão é esse, a roupa é tal" [Em alguns programas dizem que] "se você é um pouco mais cheinha, assim, daí não pode usar minissaia, não pode usar camiseta clara". E conclui a estudante: "É horrível, isso mexe com a tua cabeça". O grupo remete aos programas de TV que mostram o quanto ser magro, especialmente no verão, tornouse uma obrigação. Num programa como Malhação, eles vêem a confirmação desses mesmos enunciados: uma personagem gorda foi fazer regime e apareceu em uma cena consultando um psicólogo, em virtude do sério problema que atravessava. Esse grupo concluiu que as próprias audiências acabam por "pedir" que os personagens sejam brancos, altos e magros, "porque a gente está acostumado" a ver assim as pessoas na TV. Julgam que as mulheres seriam bem mais cruéis que os homens nessa exigência, embora todos hoje se ocupem de julgar o corpo do outro. O cotidiano dessas jovens é narrado como bastante ocupado com tamanhos de peitos e pernas, gorduras em excesso, barrigas. Quanto aos homens, povoa seu imaginário o medo de outro grande fantasma: ser gay...("Falam de gay como se fosse um monstro", diz uma das alunas). Um colega confirma: "Os caras têm medo só de ver, entendeu, dois caras se grudando...".

Quanto à homossexualidade entre mulheres, uma das alunas faz um dos comentários mais ricos da sessão de debates. Para ela, o que choca, o que incomoda é algo que "vem de longe": "Por mais que tu tente não ser preconceituoso, sempre tem uma coisa - ai, lésbica!... É uma coisa que vem, assim, é do dia-a-dia que tu pega, sem tu querer, sabe? Eu mesma não costumo ser preconceituosa, mas às vezes sai, fulano é viado, uma coisa assim...". Outra colega completa, mais enfática: "Parece que tem coisas que estão dentro da gente e a gente não sabe como foi parar lá. É horrível, é como se a sociedade te ensinasse, desde pequenininho, assim, e mesmo que tu tenha amigos homossexuais ou lésbicas, negros, gordos, sempre aparece alguma coisa, na hora, [tu acaba falando]. 'ah, aquele gordo"'. Uma das alunas de escola pública federal conclui: "acho que tu tem que ser normal. Tem um negócio [sobre isso, sobre a normalidade] que é mais forte que a gente". 
Todos esses depoimentos nos remetem ao belíssimo curso de Foucault, Os anormais, ${ }^{10}$ em que aprendemos o quanto nossos modos de classificar o outro e principalmente de julgar o que seria normal e anormal dependem de uma operação complexa e ampla, na qual estão envolvidas inúmeras instituições e práticas. Assim, podemos pensar, na esteira do pensamento foucaultiano, que os modos de existência jovem, aprendidos em nosso tempo e plenamente visíveis nos produtos dos meios de comunicação, parecem depender de classificações ininterruptas, quase incontroláveis, como referem os estudantes quando dizem que se trata de algo "mais forte do que a gente". Não há como deixar de relacionar as classificações dos jovens da pesquisa com os relatos trazidos por Foucault em seu curso, sobre a rejeição e exclusão dos leprosos, dos pesteados, dos loucos, das prostitutas, dos monstruosos. $\mathrm{O}$ aprendizado da classificação é o aprendizado da individualização, da divisão e da subdivisão do poder, "que chega a atingir o grão fino da individualidade" (FOUCAULT, 2001, p. 57).

Ora, relacionar excluídos como os pesteados do século XVIII na Europa com os obesos do século XXI no Brasil não significa dizer que todos esses rejeitados se equivalem. Trata-se, ao contrário, de mapear os modos de existência classificatórios de nosso tempo, levando em conta sobretudo que nossa sociedade é hoje pautada por algo que se poderia chamar, com Debord, de moral do espetáculo - no caso, do espetáculo midiático. Também é preciso situar concretamente como, em nosso País, se operacionaliza essa moral, de modo a ordenar e reordenar nossas vidas, a partir de um sem-número de classificações, num complexo desfile de imagens de desejáveis e de indesejáveis. Tanto Foucault como Debord, portanto, nos ajudam a situar, a pensar essas práticas classificatórias no nosso tempo e lugar, para que possamos ir adiante e produzir novas indagações, no caso, sobre a condição juvenil brasileira.

Em primeiro lugar, cabe ressaltar: nem tudo seria ditado pela mídia; existem fissuras nas produções discursivas; há possibilidades ainda não pensadas de nos constituirmos sujeitos hoje, apesar das normas e regulações que passam, sobretudo, pelos meios de comunicação. De qualquer forma, não há dúvidas de que o conceito de realidade-espetáculo, associado ao de moral do entretenimento, nos ajuda a entender melhor o complexo sentimento, experimentado pelos jovens, de livre acesso a um número infinito de imagens e informações, o qual não corresponderia a um maior comprometimento com as diferentes realidades e situações mostradas. Tudo indica que qualquer fato,

${ }^{10}$ Curso proferido em 1975 no Collège de France, em Paris. 
por mais doloroso ou belo que seja (uma doença grave, um ataque terrorista, uma estação de metrô atingida, uma plataforma de petróleo que explodiu, o escândalo de corrupção no meio político, um bebê roubado na maternidade, a descoberta de espécies raras da fauna ou da flora numa reserva florestal), não só é transformado pela mídia em espetáculo, mas também nos é narrado de tal forma que nos convida a um permanente distanciamento moral, como se aquilo ali, oferecido como espetáculo, na verdade não nos dissesse respeito.

Mais do que isso, estaríamos aprendendo dentro dessa lógica a produzir generalidades, segundo as quais se aceita que há um mundo que "vai bem", por obra e graça de alguns heróis ou celebridades; e há um mundo que "vai mal”, por obra e graça dos vilões de sempre: traficantes, políticos corruptos, trabalhadores sem-terra, arruaceiros grevistas, policiais subornados, famílias sem valores, jovens drogados (COSTA, 2004, p. 233-234). Mas, como escreve o mesmo autor, se perguntarmos quem são exatamente essas pessoas, esses jovens, esses políticos, esses baderneiros (ou, no caso de uma boa notícia, o biólogo que cuida de um animal raro em extinção), permanece a idéia de que não haveria nomes, no sentido de que esses aí são "o outro", são aquele que não é nenhum de nós em particular; ou seja, trata-se definitivamente de "outros". Ora, segue o autor, é isso que acaba por nos isentar de qualquer responsabilidade cívica ou moral. E é diante dessa realidade que se encontram os jovens e as crianças de nosso tempo, em relação aos quais temos, como educadores, muito a dizer - ou a escutar. Estariam os jovens e as crianças sendo construídos como "outros" que, paradoxalmente, amamos e rejeitamos? Como isso estaria ocorrendo? E de que modo a mídia se associaria aos educadores e à sociedade mais ampla, no sentido de nomear e classificar esses "outros" jovens?

\section{Os "outros" subcidadãos em meio a tribos urbanas}

Do ponto de vista social mais amplo, há, sabemos, "outros" que nos intimidam, que batem à nossa porta, que fazem piruetas na esquina do semáforo, que se postam diante das vitrines do shopping com seus bonés e seus olhares por vezes inquisidores e inquiridores - estes configuram uma ampla maioria em nossa sociedade. Seriam os "subcidadãos" de que nos fala Jessé de Souza (2003). Já nas menores microrealidades também parece proliferar uma quantidade imensa de vários "outros”, distribuídos pelas diferentes ca- 
madas sociais, e que hoje estariam diretamente vinculados à cultura somática de si mesmo, àquilo que Jurandir Costa (2004) tão bem denomina de "cultura das sensações" ou de "subjetividade exterior". Esses dois grupos de "outros" habitam tanto os programas de TV por nós analisados, como os debates que essas produções instigaram entre os jovens das turmas de recepção, nos grupos em que realizamos a pesquisa.

Numa das escolas públicas, por exemplo, a discussão sobre as classificações mostrou-se fortemente relacionada à posição social, à disponibilidade financeira das pessoas. Embora alguns referissem que ter ou não ter posses é algo que não interessa ("Quem tem, tem, quem não tem não vai ser excluído porque não tem dinheiro" - como diz uma das alunas), vários estudantes afirmaram que os grupos muitas vezes se constituem a partir dos que têm ou não têm "grana". Um dos alunos forneceu o exemplo mais curioso, mas totalmente típico de nossa época: contou que foi julgado pelos colegas porque o tênis dele era "de camelô", não era "de verdade". Nesse grupo, a discussão encaminhou-se para a necessidade de trabalhar, de ter o próprio dinheiro, ${ }^{11}$ diferente do que o programa da Rede Globo havia apresentado, de jovens que recebem tudo dos pais, ou de pessoas que, mesmo trabalhando, são capazes de gastar um salário inteiro com uma "calça de marca". De qualquer forma, no debate estava viva a força do externo, da roupa, do tênis, da moda: eles não titubearam em concordar que "a personalidade muda" [a partir de uma] "característica exterior".

Conforme Costa, nossa sociedade estaria promovendo, com o apoio fundamental do mercado e dos meios de comunicação, personalidades narcisistas, hedonistas, de modo que os mais jovens, desde cedo, estariam aprendendo que a auto-realização confunde-se com "sucesso econômico, prestígio social ou bem-estar físico e emocional” (COSTA, 2004, p. 185). Cuidar de si é obter todo tipo de satisfação sensorial, que passa, inevitavelmente, pelo julgamento da aparência física, dos modos de vestir, dos lugares que se freqüenta, das pessoas com quem se anda. Perde-se aí, segundo o autor, uma perspectiva que considere os longos prazos e os objetivos extra-pessoais - indispensáveis se quisermos pensar na formação de cidadãos cujo interesse se volte para as questões públicas e políticas mais amplas, articuladas com as pequenas lutas cotidianas.

${ }^{11}$ Também aqui nossa pesquisa corrobora os dados de "Perfil da juventude brasileira", investigação que mostrou o quanto o item "trabalho" aparece para os jovens como algo extremamente positivo, relacionado a independência, crescimento e auto-realização (cf. ABRAMO, 2005, p. 53). 
Quanto a outros programas de televisão, em que camadas menos favorecidas da sociedade brasileira são mostradas, como ocorreu com a minissérie Cidade dos Homens, ${ }^{12}$ parece que os jovens - no caso, de classe média e de escola particular - vivem um conflito bem claro: sentem-se "constrangidos" com a pobreza, quando colocados diante daqueles que "não têm nada", e acabam por evidenciar tudo o que separa esses dois mundos sociais. Quando têm a oportunidade de conviver com amigos pobres, sentem-se mal, por terem carro, por terem roupas boas para vestir; sentem-se invadindo um outro mundo, sentem medo, e isso é expresso já pelos pais, inconformados com a amizade do filho, a aproximação com esse "outro" social. "Me sinto meio impotente, de não poder fazer nada...", diz um dos alunos. Outros relatam episódios de assaltos, ou de arrastão em dias de jogos de futebol, falam de medo e ao mesmo tempo do "beco sem saída" dos mais pobres, dos que habitam favelas e vilas nas grandes cidades, da opção pela violência, já que "o meio obriga", como disse um dos meninos. E completou: "[Eles] não têm mesmo o que perder".

A discussão encaminhou-se nesse grupo para a diferenciação entre pobreza e miséria, entre pobreza e violência, entre dar ou não esmola aos que pedem e estão na rua. Meninos e meninas de 16 anos lembram que a realidade mais ampla é que é violenta; é isso que permite, por exemplo, uma criança, em tantos lugares do mundo, inclusive no Brasil, ser levada a matar, a carregar uma enorme arma como ato "normal" de seu cotidiano. Repetem chavões conservadores sobre pobreza no Brasil, como o de que, quando uma pessoa pobre recebe esmola, sempre "quer mais e mais", e o de que "o cara podia tá trabalhando, podia ganhar dinheiro", como diz um dos alunos, imediatamente questionado por outro colega: "Mas oportunidade de trabalhar não é assim...”.

Os outros - pobres, marginais, homossexuais, negros - são mencionados e tratados com as ferramentas que essa geração parece ter: uma certa tolerância e, ao mesmo tempo, a perplexidade diante do preconceito que habita cada um deles e o tímido desejo de transformar essa realidade. Os alunos da escola particular afirmam, por exemplo, que nunca foram atendidos por um médico negro ou por um gerente de banco negro. E, se isso acontecesse,

${ }^{12}$ A minissérie Cidade dos homens, da Rede Globo de Televisão e da produtora 02 Filmes, foi exibida em três temporadas, desde 2002, e gira em torno dos personagens Acerola e Laranjinha, moradores de uma favela na Zona Sul do município do Rio de Janeiro. Teve origem no filme Cidade de Deus (2002), com direção de Fernando Meirelles. 
assumem que ficariam surpresos: "Pô, um cara negro, que é isso?". Admitem que somente quando não houver mais essa surpresa "tudo vai tá igual". O mesmo menino pergunta: "Tu acha que as pessoas negras têm as mesmas oportunidades que nós? Olha aqui, meu. (...) Não têm. Olha o favelado. Tu acha que aquela pessoa tem oportunidade de ser médico, trabalhar, fazer uma faculdade de direito?". Esse menino, apesar da indignação, acaba o raciocínio, de forma um tanto conformista: "Quando todo o mundo trabalhar no mesmo plano, quando tudo tiver igual, a gente vai conseguir olhar igual. Agora não dá". Outro colega completa: “... nunca vai acontecer esse esquema de poder olhar tudo igual".

Poderíamos dizer que os depoimentos, nos seis grupos de recepção, apontam para um fato que não se pode desconsiderar: a percepção, mesmo que não claramente formulada em muitos casos, que esses jovens têm de que os processos classificatórios, em nossa sociedade, contam com a participação permanente dos meios de comunicação, no sentido de estes produzirem alguns efeitos de verdade sobre todos os tipos de "outros". Os modos de mostrar os outros sociais (sejam os que efetivamente estão do outro lado da rua social, sejam todos os outros-diferentes, as tribos mais diversas de jovens) parecem construir-se segundo uma lógica narrativa que privilegia os guetos, as separações, a não-mistura, a identificação de tribo com roupa e consumo, a cristalização de imagens em que jamais se poderiam perceber quaisquer nuances. Uma das alunas do colégio público federal chega a uma conclusão: “A TV ajuda as pessoas a serem mais preconceituosas do que já são!". Outro colega, nessa mesma escola, concorda: [a TV] "passa uma imagem de que essas pessoas [os pobres] são uma ameaça para nós". Uma das estudantes de Pedagogia, por sua vez, parece complementar o raciocínio dos estudantes de Ensino Médio: "Aprendemos que drogas é horrível nas classes populares, que os pobres é que são o problema". Outra completa: "[O medo dos pobres] é automático!".

Da mesma forma que os outros-pobres se transformam em seres indesejáveis e guetizados, alguém para ficar "longe de nós", as diferentes tribos jovens também merecem um tratamento guetizante e estereotipado. No dia da exibição da reportagem do telejornal Hoje, da Rede Globo, os calouros de Comunicação Social comentaram que, para o jovem chegar a saber quem ele é, precisa achar sua "tribo", "porque tu não sabe quem tu é, se tu não pegou umas pessoas assim como tu e que também gostam de ti...", como diz um dos alunos. Segundo esses estudantes, podemos pertencer simultaneamente a várias tribos, e estas parecem estar vinculadas principalmente a gostos e modas musicais, diferentemente do que é mostrado na reportagem da TV, em que a 
associação entre tribo e consumo parece predominar, reforçando uma prática que ocorre entre os jovens, de passar a pertencer a uma tribo a partir da adoção de um tipo de vestimenta. "O pessoal que é punk mesmo tem razão de não gostar desses punks de butique", assinala um dos estudantes. Outra aluna lembra que as tribos de hoje estão mudando muito rapidamente, por influência direta da mídia, mas acredita que

as primeiras tribos que existiram surgiram por causa das diferenças de pensamento numa sociedade liberal. A gente pode lembrar os hippies, os punks, que surgiram por quê? Porque tinham valores completamente diferentes. Eu acho que na atualidade a gente tá vivendo num período tão individualista que não importa, não tá importando mais o pensamento das pessoas (...). É um estilo de pensar ou é um estilo de vestir? (...) Só o que a sociedade espera de mim, que eu seja uma pessoa, não mais uma na multidão, que eu tenha o meu próprio estilo. Só que qual é o meu estilo? Não seria o meu estilo de pensar, seria o meu estilo de vestir. Eu acho que tem uma banalização dessas tribos.

Os alunos da escola particular, por sua vez, mostraram estar aprendendo que nos reality shows constrói-se uma narrativa propícia a reunir elementoschave de uma cultura que, cinicamente, afirma: estamos todos num jogo, quem for mais esperto vai ganhar, que "para se dar bem, vai pisar em cima dos outros pra subir", como afirma um dos meninos. Outro aluno complementa, indagado sobre a prática de "detonar", "eliminar", "mandar para o paredão": "Eu acho que [isso] incentiva mais o individualismo, assim, mais do que a sociedade já está individualista". A turma é unânime em afirmar o quanto, na mídia, aprendem que "não é necessário ajudar ninguém, porque ninguém vai te ajudar". Um dos alunos, provocador, rebate: "Se eu entrasse num esquema desse aí $[B B B]$, eu ia entrar pra pisar na cabeça de todo mundo. Entrar num programa desse aí é pra fazer isso!". Ajudar o outro, segundo o $B B B$, para alguns desses alunos, seria fazer o papel de "otário".

Os depoimentos corroboram o que diz Maria Rita Kehl: para ela, a grande excitação de programas como os reality shows não seria exatamente a exibição de cenas eróticas ou de revelações picantes. "O que excita o pessoal é o paredão. Conspirações, traições, armadilhas, estratégias descaradas para passar a perna nos companheiros e garantir a própria permanência: este é o tema de BBB" (KEHL, 2004, p. 171). Conforme atestam os jovens de nossa pesqui- 
sa, parece que esse tipo de programação estaria em harmonia com certas verdades de nossa época, segundo as quais o eu narcísico deve ser satisfeito a qualquer preço e rapidamente, já que espaços institucionais públicos de todos os tipos, como a própria escola, não estariam dando conta das demandas simbólicas dos diferentes grupos sociais. Ali, no Big Brother, ou em tantos outros programas, a TV nos diz que está perto de nós, é rápida e transparente, fala a cada um, melhor do que qualquer outro lugar social, oferecendo uma proximidade imaginária que reforça a descrença no fortalecimento de outras instâncias de vida pública e simbólica.

\section{Invenção de novos espaços simbólicos: que possibilidades?}

Nos depoimentos dos seis grupos, chamou a atenção o entusiasmo com que os universitários de Comunicação se referiram a uma das escolas públicas estaduais mais conhecidas de Porto Alegre, ${ }^{13}$ e que aliás também fez parte da pesquisa. O Colégio "Julinho" se transformou historicamente numa grande tribo, a "tribo mais famosa", porque lá permanece uma idéia de "revolução", de movimento esquerdista, como referem os alunos. Eles trazem para o centro da discussão uma escola que já completou 100 anos e que se caracterizou historicamente por uma participação política muito atuante e crítica, particularmente nos anos 60 e 70, e da qual a sociedade gaúcha ainda guarda memória. Ou seja, parece afirmar-se, nesses depoimentos, uma possibilidade diferenciada de vida pública, mas que talvez ainda assim fique como uma realidade que não nos pertence, que é de um "outro", o "outro" daquela escola, alguém que eu não sou e talvez nem possa vir a ser...

Entendo que essa lembrança seria emblemática de outros acontecimentos vividos com os grupos de recepção: momentos de adesão e ao mesmo tempo de crítica à TV; momentos de perplexidade, de dúvida e de confronto com as próprias crenças. Afinal, sou aberto à liberdade de escolhas sexuais? Afinal, concordo com o preconceito estampado na tela da TV, sobre gays e lésbicas, tanto quanto as personagens das novelas? Por que tenho medo dos

${ }^{13}$ Eles se referem ao colégio apelidado carinhosamente de "Julinho", o Colégio Estadual 25 de Julho". Ver, a propósito, a dissertação de mestrado de Eliane Dable de Mello, sobre os jovens dessa escola de Porto Alegre (MELLO, 2004). 
pobres? Por que tenho medo da rua e me enfurno em casa, assistindo a seis horas de TV por dia? O que encontro nos outros grupos e tribos que freqüento e que difere tanto daquilo que a mídia me mostra? Perguntas como essa povoaram todos os debates, acionados pela exibição de trechos de programas de TV e anúncios publicitários. Eu diria que a análise dos programas de televisão, feita nas escolas, e sob a forma de debate, abre para nós, educadores, um conjunto de outras questões, relativas ao problema maior da dimensão pública da existência.

É disso que trata o último curso de Michel Foucault, no Collège de France, intitulado A hermenêutica do sujeito e publicado com o mesmo título (FOUCAULT, 2004). Nessas aulas do filósofo, emerge a problematização do que somos hoje, ou do que seria em nosso tempo a possibilidade de lutarmos por uma "ética dos cuidados de si", diferente da ética narcísica e individualista da moral do espetáculo. É bem verdade que Michel Foucault nos descreveu o que foi, para os gregos e romanos clássicos, toda a produção de uma tecnologia de si mesmo, voltada para o aperfeiçoamento de si e em prol de uma ação política, de uma atuação na polis. De qualquer forma, entendo que, embora todos os esforços de nossa cultura, em direção ao apagamento do sujeito da ação política, como refere Maria Rita Kehl (2004), haveria uma demanda, expressa em várias passagens dos depoimentos dos jovens, a respeito da expressão de si, para além da performance narcisista que nos é hoje tão familiar. Essa demanda aparece também, esporádica e espasmodicamente, em alguns produtos da TV brasileira e de outros países, e esse é o caso de séries como Cena aberta, ${ }^{14}$ da Rede Globo, ou de entrevistas e documentários especiais da TV Cultura de São Paulo ou de canais a cabo, como o GNT.

Imagino que um dos trabalhos de estudiosos de educação e comunicação poderia ser o de apontar essas fissuras na cultura midiática de nosso tempo, seja a partir da análise de produtos dos diferentes meios de comunicação, seja a partir de estudos de recepção, especialmente com crianças e jovens. ${ }^{15}$ Tanto nos produtos da mídia como nos usos que se faz deles - conforme vimos acima -, parece emergir não só um desejo de pensar o momento que vivemos como de lembrar que podemos fazer de nossas vidas uma arte: arte que diz respeito a pensar sobre si mesmo, cuidar de si, preparar-se para viver cada dia pois, como nos ensinaram filósofos antigos, nossa vida inteira é uma prova. Sendo assim,

${ }^{14}$ Série de cinco programas da TV Globo, em que se misturam ficção, literatura e documentário. Apresentado por Regina Casé, estreou em novembro de 2003.

${ }^{15}$ Ver, a respeito, algumas propostas sobre práticas de pesquisa e de intervenção na escola, a partir de estudos das imagens midiáticas, em FISCHER, 1996; 2002; 2003. 
temos que nos preparar, todos os dias, equipando-nos para qualquer tipo de acontecimento ou imprevisto. Estudar a mídia e o que seus produtos nos propõem como modos de existência - no caso, modos de existência jovem - constituiria, à maneira de Foucault, uma possibilidade de participar da elaboração de uma história do que fizemos de nós mesmos para sermos o que somos na atualidade. Ou seja, podemos descrever como se vão tecendo - nas construções da mídia e nas interações de diferentes públicos com essas produções - algumas formas específicas de ser e estar no mundo e neste país.

Descrevi mais demoradamente, neste texto, modos pelos quais grupos jovens de camadas médias e baixas da população, em Porto Alegre (RS), se relacionam com produtos televisivos a elas dirigidos. Especificamente, tratei de estratégias de construção de "outros", de diferentes, as quais emergem na fala de jovens de 15 a 25 anos, diante da TV. Trata-se de falas mestiças, complexas, plenas de perplexidade e dúvidas, formuladas por dentro de uma sociedade em que vigora a moral do espetáculo e a lógica do entretenimento. Apoiada em Michel Foucault, defendo que não podemos abandonar a discussão política em relação ao que nossa sociedade tem proposto que sejamos nós, nossa vida, nossos corpos, nossas formas de ser jovem. Mas junto a essa análise que leva em consideração o poder e os modos de sujeição na cultura, buscamos mostrar que as inquietações de homens e mulheres jovens - sobre si mesmos, sobre o aprendizado que percebem em si a respeito das classificações de si e dos outros - podem ser tratadas como uma possibilidade de ação política, de exercício sobre si mesmo, visibilidade, mesmo que tênue, de um modo de subjetivação para além dos poderes e sujeições contemporâneos.

\section{REFERÊNCIAS}

ABRAMO, H. W. Condição juvenil no Brasil contemporâneo. In: ABRAMO, H. W.; BRANCO, P. P. M. (Orgs.). Retrato da juventude brasileira. São Paulo: Fundação Perseu Abramo/Instituto Cidadania, 2005. p. 37-72.

ABRAMO, H.; FREITAS, M. V.; SPOSITO, M. P. (Orgs.). Juventude em debate. São Paulo: Cortez/Ação Educativa, 2000.

COELHO, T. O imaginário da morte. In: NOVAES, A. (Org.). Rede imaginária. Televisão e democracia. São Paulo: Cia. das Letras/Secretaria Municipal de Cultura SP, 1991, p. 109-122.

COSTA, J. F. O vestígio e a aura. Rio de Janeiro: Garamond, 2004. 
DEBORD, G. A sociedade do espetáculo. Rio de Janeiro: Contraponto, 2002.

FISCHER, R. M. B. Adolescência em discurso: mídia e produção de subjetividade. Porto Alegre, 1996. Tese (Doutorado em Educação) - Programa de Pós-Graduação em Educação, Universidade Federal do Rio Grande do Sul.

. Mídia, juventude e reinvenção do espaço público. Porto Alegre, 2005. Relatório final de pesquisa. Departamento de Estudos Especializados, Faculdade de Educação, Universidade Federal do Rio Grande do Sul.

. O mito na sala de jantar. 2. ed. Porto Alegre: Movimento, 1993.

. Problematizações sobre o exercício de ver: mídia e pesquisa em educação. Revista Brasileira de Educação, Rio de Janeiro, n. 20, p. 83-94, maio/ago. 2002. 2003.

. Televisão \& educação: fruir e pensar a TV. 2. ${ }^{a}$ ed. Belo Horizonte: Autêntica,

FOUCAULT, M. A arqueologia do saber. Rio de Janeiro: Graal, 1986.

. A hermenêutica do sujeito. São Paulo: Martins Fontes, 2004.

. História da sexualidade I. A vontade de saber. Rio de Janeiro: Graal, 1990.

. Os anormais. São Paulo: Martins Fontes, 2001.

. O sujeito e o poder. In: DREYFUS, H.; RABINOW, P. Michel Foucault, uma trajetória filosófica (para além do estruturalismo e da hermenêutica). Rio de Janeiro: Forense, 1995. p. 231-249.

. Vigiar e punir. Petrópolis: Vozes, 1991.

KEHL, M. R. Três observações sobre os reality shows. In: BUCCI, E.; KEHL, M. R. Videologias. São Paulo: Boitempo, 2004. p. 165-173.

LARROSA, J. Educação e diminuição. In: Linguagem e educação depois de Babel. Belo Horizonte: Autêntica, 2004. p. 265-294.

MELLO, E. D. Juventude e utopia: experiências entre os muros de uma escola pública. Porto Alegre, 2004. Dissertação (Mestrado em Psicologia Social) - Instituto de Psicologia, Universidade Federal do Rio Grande do Sul.

SARLO, B. Cenas da vida pós-moderna: intelectuais, arte e videocultura na Argentina. Rio de Janeiro: UFRJ, 1997.

SOUZA, J. A construção social da subcidadania. Belo Horizonte: UFMG, 2003.

Texto recebido em 02 mar. 2005

Texto aprovado em 11 jun. 2005 